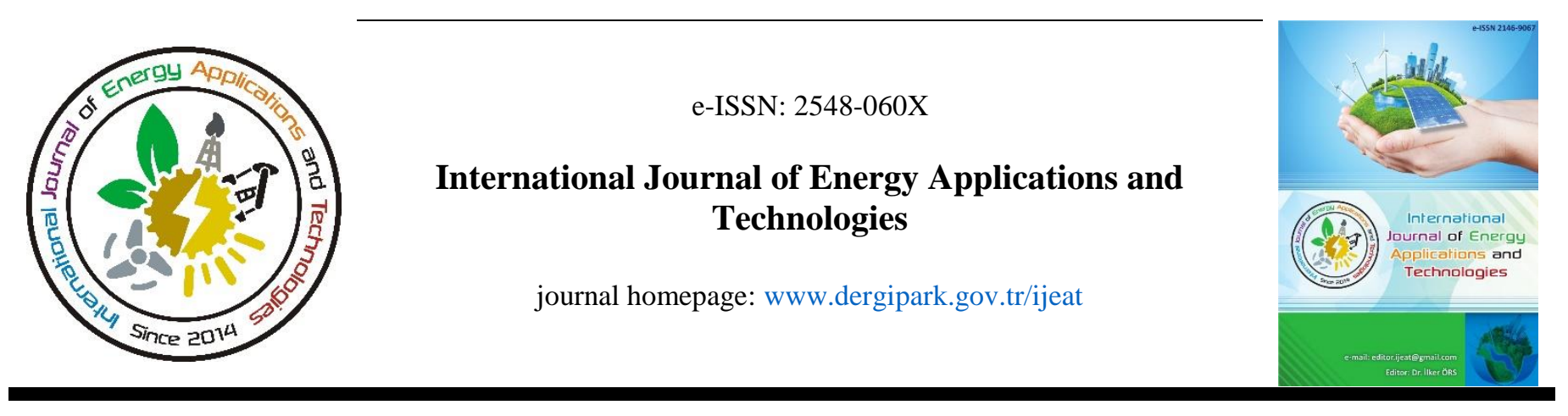

Original Research Article

\title{
Generation unit sizing, economic analysis of grid connected and standalone PV power plant
}

hosted by JourkinhalPark

\author{
Maher Al-Maghalseh \\ College of Engineering, Palestine Polytechnic University, Hebron, Palestine \\ Renewable Energy and Environmental Research Unit (REERU), Palestine, Polytechnic University, Hebron, Palestine
}

\author{
ARTICLE INFO \\ * Corresponding author \\ maherm@ppu.edu \\ Received July 16, 2018 \\ Accepted February 12, 2019 \\ Published by Editorial Board \\ Members of IJEAT \\ (C) This article is distributed by \\ Turk Journal Park System under \\ the CC 4.0 terms and conditions. \\ doi: $10.31593 /$ ijeat.444091
}

\begin{abstract}
This paper presents a design for a grid connected PV system with the capacity of 1.5 MVA, as well as a standalone PV system with the capacity of $50 \mathrm{kVA}$ in the West Bank industrial zone, Palestine. The factors affecting the design and size of the system are also presented and evaluated. To ensure adequate, reliable and economical system design, over and under sizing energy has been avoided. Furthermore, a numerical analysis will be carried out to evaluate the effects of the grid-connected system on the network, with respect to the voltage profile, power flow, and energy losses. The results have shown a good enhancement in the total energy losses and voltage profile in reference to load and generation capacity. However, the voltage profile is enhanced on buses located close to the proposed PV plant while the profile enhancements decrease when moving closer to the source buses. The maximum increase in voltage profile is $0.4 \%$ which is satisfactory in our case. Furthermore, the power losses were clearly decreased with installed of PV systems. Finally, an economic analysis for both systems will be presented. It was found that the total income of the project is expected to be around $\$ 616,923$ per year. Further, the payback period is expected to be .5 years and the Net Present Value (NPV) is about $\$ 3,885,125.91$. The Internal Rate of Return (IRR) for the project during a 20 -year lifespan is about $26 \%$.
\end{abstract}

\section{Introduction}

The power sector in Palestine is outdated and has been neglected for several years. That said, it unreliable, aged and inefficient. The system is frequently overloaded and critical energy shortages and failures are a constant occurrence. The generator depends on Israeli sources to the tune of $92 \%$, with the remainder of supply secured through interconnection points with neighboring countries, including Jordan and Egypt. Recently, the Palestinian Energy Authority (PEA) set out a strategy to develop it's power sector. The strategy focused on rehabilitating existing networks and extending services to under-served communities. It also targeted the implementation and development of the transmission system.
Further aims included an increase in system capacity and reduction of electrical supply dependency on Israel. Here alternative and sustainable solutions are essential. Generating electricity using renewable energy has become a national strategy. Specifically, the expansion of the use of solar energy toward a dependable and fully adequate supply of clean energy to residential, commercial and industrial consumers,

The Jericho district, in a vital location with its proximity to the Jordanian border, offers expansive land resources at relatively decent pricing, has witnessed rapid economic growth and increased competition among investors. This huge demand for energy supply, especially in the industrial sector, has pushed the Jerusalem District Electricity 
Company (JDECO) to look for alternative solutions to attract investment in renewable energy projects in Jericho.

PV systems are considered a main renewable energy source, particularly in Jericho because of its unique geographical location, climate, topographical profile and average yearly solar radiation received. There are two general types of electrical designs for PV power systems; the grid connected system which interacts with the utility power grid and does not utilize a backup battery capability; and standalone systems which interact with the utility grid and include battery backup $[1,2]$. A grid-connected system is designed to operate parallel with an electric utility grid and can range from small residential and commercial rooftop systems to large utility scale systems. On the other hand, standalone solar power systems have been used for several years in areas where no public grid is available. Moreover, they operate with stored energy by charging a bank of batteries [3, 4]. Luo et al. [5] numerically studied the influence of PV-STATCOM on voltage recovery efficiency under voltage sag conditions. The model was applied in IEEE 33-bus distribution system under several scenarios. The study proposed an optimal siting and sizing model for the purposes of minimizing the total annual costs related to the distribution generation to be planed.

Freitas et al. [6] numerically evaluated the influence of large scale PV on the sizing and grid capacity in urban distribution network. Two methods were used to estimate the PV potential to be developed in the system. These are the peak power method and intensive irradiance method. It was found that the Peak power method has limited success if PV facades are to be considered. Moreover, a high PV penetration scenario leads to a locally less flexible grid. Abushnaf and Rassau [7] presented a numerical model to study the optimal size of grid connected hybrid PV/battery system with home energy management system. The system was tested under different cases of charging and discharging. Das and Akella [8] presented a numerical model to control the power flow of hybrid standalone PV system with wind battery PV system. The renewable energy systems were used as a backup to balance the power flow between the generation and the demand. Mandal et al. [9] conducted a feasibility study of using a hybrid energy system include PV, Wind, and Diesel with battery storage system in rural distribution network. Several system configurations were numerically evaluated and an optimized system was selected to meet the local demand.

Hamrouni [10] developed a numerical model using MatlabSimulink to study the effects of the grid connected PV system on the grid. The proposed methods aim to improve the quality of power by injecting the generated power into the grid at unity power factor and a current with low harmonic distortion. Maammeur [11] conducted a comprehensive literature review for the grid connected PV system as well as an economic and technical analysis for cattle farms in the Chlef district (north-west of Algeria). Kazem [12] presented an economic analysis and optimum design for PV standalone pumping system for rural areas in Oman. Maghalseh [13] studied the optimum sizing and location for the PV systems to improve the voltage profile and reduce losses in the grid. A considerable amount of literature has been published on PV grid connected and standalone systems [2, 14-20]. These studies analyzed the economic and technical methods for integrating the PV grid connected systems.

In this study, the design for grid connected and standalone PV systems with the capacity of 1.5 MVA is examined. For this purpose, the sizing of the system, optimum location, and the economic and technical analysis were presented.

\section{The Potential of Solar Energy}

The potential for the success of solar power in Palestine is high due to the abundance of solar radiation received yearly in comparison with neighboring countries. Fig. 1 shows the values of global irradiation in the Jericho industrial area (Lat. 31.84N, Long. 35.48 E, Alt. $-294 \mathrm{~m}$ ). The annual daily average solar irradiation in Palestine is estimated to be 5.46 $\mathrm{kWh} / \mathrm{m}^{2}$. The average solar radiation during the winter season is approximately $3.5 \mathrm{kWh} / \mathrm{m}^{2}$.day and it exceeds $6.242 \mathrm{kWh} / \mathrm{m}^{2}$.day during the rest of the year. The location of PV plant in Jericho was chosen for its proximity to the new industrial area in the southern east part of the city in order to cover part of the expected industrial load in the region.

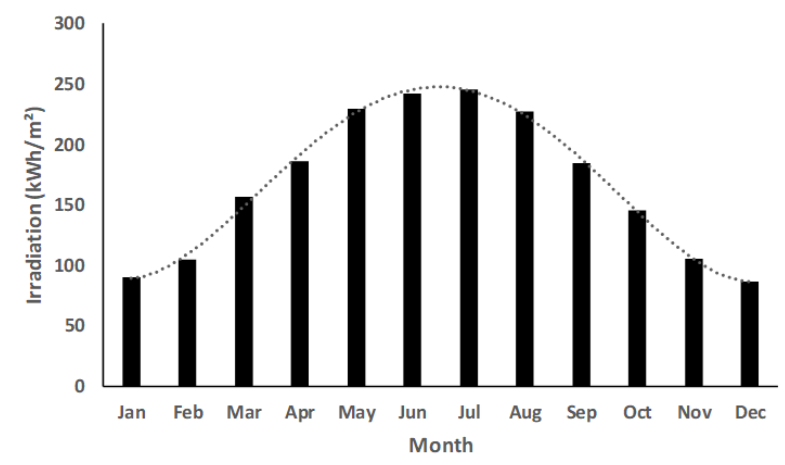

Figure 1. Monthly average global solar radiation $\left(\mathrm{kWh} / \mathrm{m}^{2} \cdot \mathrm{mth}\right)$ in Jericho

\section{Design of PV system}

The design of system components was selected according to the required peak power from the plant. The peak power is estimated to be about $1.5 \mathrm{MW}$. The panel generation factor (PGF) is a common factor which is used to estimate the required PV panel modules. It depends on the intensity of radiation, location and sunshine hours. 


$$
\text { PGF }=\frac{\text { solar irradiation } \times \text { sunshine hours }}{\text { STC } \text { irradiation }}=\frac{698 \times 9}{1000}=6.28
$$

The total energy required from the PV plant in the Jericho industrial zone is approximately 7.2 MWh/day. Energy loss in the PV system $=30 \%$. Subsequently, the required energy from the PV modules:

$E=1.3 \times 7.2=9.36 \mathrm{MWh} / \mathrm{day}$

By dividing the total energy required from the PV plant by the PGF, the peak rating of the PV modules can be calculated: Peak rating $=\frac{E}{P G F}=9.36 \mathrm{MWh} / 6.28=1.49 \mathrm{MW}$

The number of PV modules required can be calculated as the following:

$$
N=\frac{\text { Total Peak Power }}{\text { Module Rated Power }}=\frac{1.49 M W}{320 W}=4657
$$

Two types of inverters were used in the design. The total power peak for type 1 and type 2 are 50 and $27 \mathrm{~kW}$, respectively. The main feeder connected to the plant is a $33 \mathrm{kV}$ feeder supplied by the Jordanian connection point with a maximum capacity of 20MVA. Three substations were constructed in the plant. Each station employed a step up transformer $0.4 / 33 \mathrm{kV}$ with rated power of $630 \mathrm{kVA}$. Each transformer is fed from main AC distribution board connected to the AC output of the on grid inverters. Furthermore, the first substation is fed from nine type 1 inverters. Each inverter is connected with nine strings, each string has 20 solar panels. The same procedure is repeated in the second substation. Finally, the third substation is fed from 23 of type 2 inverters. Each inverter is connected with 5 strings, each string includes 18 solar panels. Fig. 2 illustrates the PV plant block diagram of the grid connected PV system. The second design features standalone PV system with the capacity of $50 \mathrm{~kW}$. The specifications of the batteries used in the system are: Total battery watt hour used per day is $240 \mathrm{kWh} /$ day, battery loss is $15 \%$, depth of discharge of battery is $50 \%$, nominal battery set voltage is $110 \mathrm{~V}$, days of autonomy is 1. Using Mutlu Batteries (2V 200Ah/ Cell), the battery capacity and total number of batteries can be calculated as:

$$
\begin{aligned}
& B C(A h)=\frac{\text { Total watt hours per day } \times \text { days }}{(0.85 \times 0.5 \times \text { Battery Voltage })} \\
& =\frac{240 \times 10^{3} \times 1}{(0.85 \times 0.5 \times 110)}=5,134 \mathrm{Ah}
\end{aligned}
$$

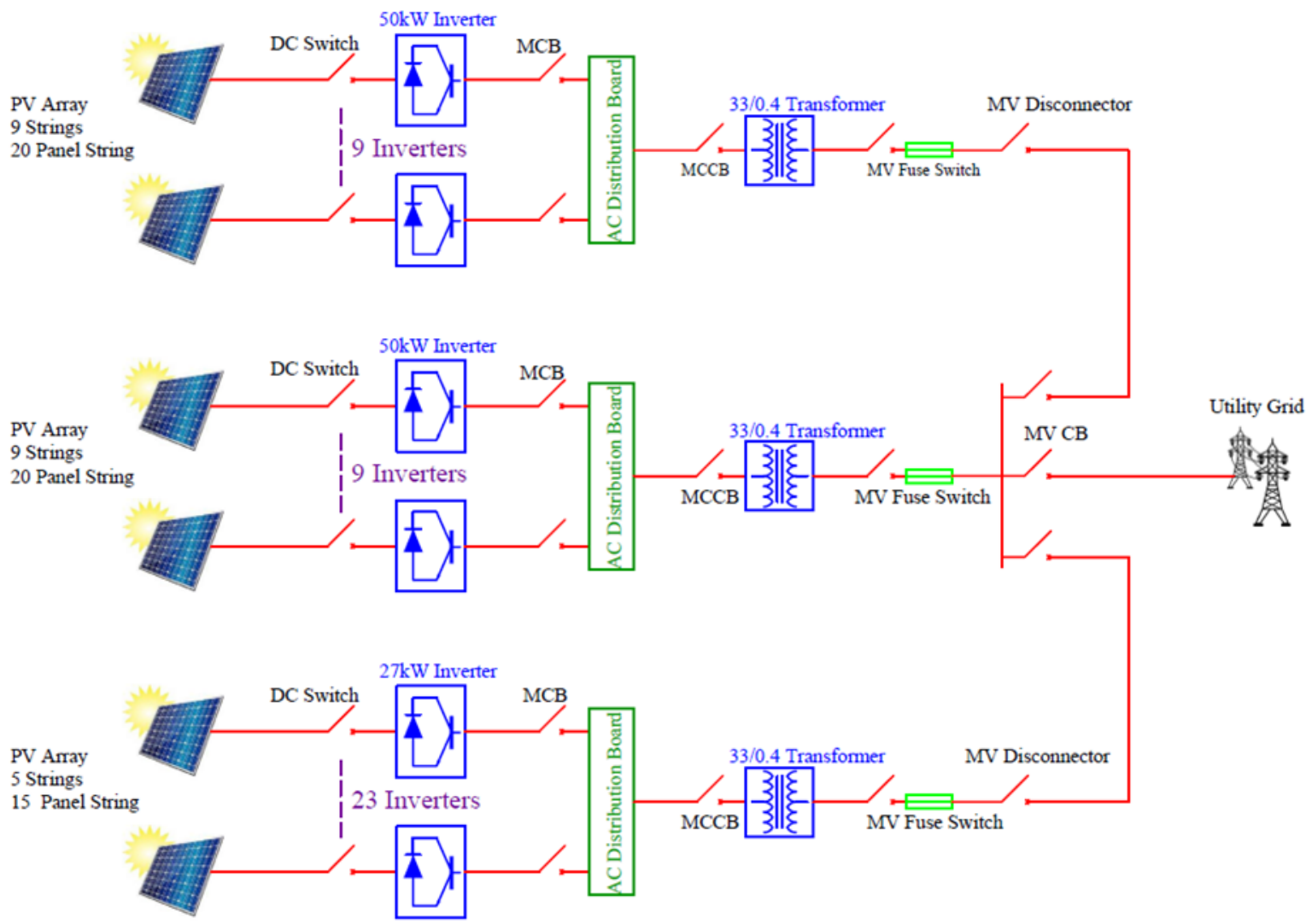

Figure 2. Grid connected PV system 
Number of parallel sets $=\frac{5134}{200} \approx 26$ sets

Number of batteries in series $=\frac{110 \mathrm{~V}}{2 \mathrm{~V}}=55$ batteries

Total number of batteries $=26 \times 55=1430$ batteries

\section{Integration with the Grid}

Fig. 4 shows the integration of the PV plant to the $33 \mathrm{kV}$ grid network. The network consists of 17 buses with a maximum load of 22 MVA. Jericho is supplied by two main sources. These are located at bus 1 and bus 4 . There are two existing PV plants connected on the network. The first is the Dead Sea plant with a capacity of $720 \mathrm{kVA}$ and located at bus 3 (PV1).
The second is the Industrial Area plant with a capacity of 300 $\mathrm{kVA}$ and located at bus 5 (PV2). The proposed location of the new PV plant (PV3) is located at bus 6 with a proposed capacity of 1.5 MVA.

A simulation study was carried out using the Open Distribution Source Simulator (OpenDSS) to simulate several cases of network with the proposed PV plant generation. Four case studies were considered under this study, these are: Case (1): Study without PV plant and with minimum load. Case (2): Study without PV plant and with maximum load. Case (3): Study with minimum PV generation and with maximum load. Case (4): Study with maximum PV generation and with minimum load. All line parameters were gathered and tabulated in Table 1. Table 2. illustrates the load points within the Jericho city limits.

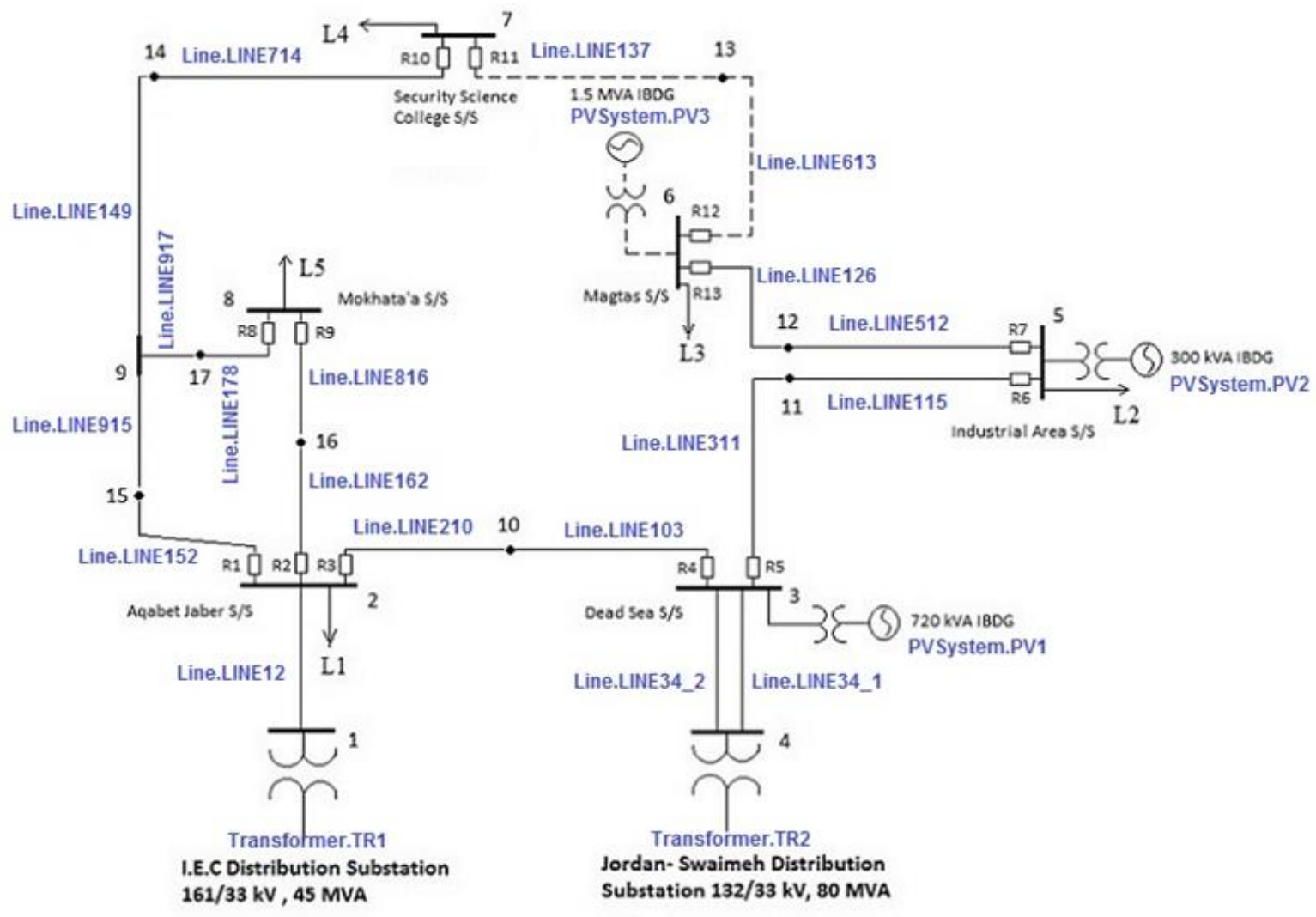

Figure 4. 33kV Single line diagram for the Jericho electrical grid with the proposed PV plant

As illustrated by Fig. 5, the voltage profile is enhanced on buses located close to the proposed PV plant while the profile enhancements decrease when moving closer to the source buses. The maximum increase in voltage profile is $0.4 \%$ which is satisfactory in our case. Furthermore, the maximum increase in voltage profile depends on the situation of the load under study. For instance, for larger penetration of PV plant, the increase in the voltage profile will be greater. In addition, from Fig. 6, one can clearly notice a decrease in power loss from $0.7 \%$ on average for case 1 to $0.39 \%$ for case
4. This means a $0.45 \%$ overall reduction in the total losses. Moreover, power flows in the system are illustrated in Fig. 7.

\section{Economic Analysis}

The aim of the financial analysis is to determine and compare the profitability of the construction of the PV plant in Jericho. The financial analysis of the PV plant gives an evaluation of potential additional or rising income and costs [21-23]. Table 3 shows the analysis for constant costs analysis, while the operation costs are illustrated in Table 4. 
Table 1. $33 \mathrm{kV}$ line parameters of the Jericho grid

\begin{tabular}{lllll}
\hline $\begin{array}{l}\text { from } \\
\text { Bus }\end{array}$ & to & Length $(\mathrm{m})$ & $\mathrm{R}(\Omega / \mathrm{km})$ & $\mathrm{X}(\Omega / \mathrm{km})$ \\
\hline 1 & 2 & 16,000 & 0.214 & 0.201 \\
2 & 10 & 1,355 & 0.268 & 0.245 \\
10 & 3 & 1,355 & 0.268 & 0.245 \\
3 & 4 & 29,200 & 0.1038 & 0.101 \\
3 & 4 & 29,200 & 0.1038 & 0.101 \\
3 & 11 & 2,030 & 0.243 & 0.23 \\
11 & 5 & 2,030 & 0.243 & 0.23 \\
5 & 12 & 1,805 & 0.2267 & 0.215 \\
12 & 6 & 1,805 & 0.2267 & 0.215 \\
6 & 13 & 1,550 & 0.214 & 0.201 \\
13 & 7 & 1,550 & 0.214 & 0.201 \\
7 & 14 & 3,530 & 0.2853 & 0.265 \\
14 & 9 & 3,530 & 0.2853 & 0.265 \\
9 & 17 & 776 & 0.214 & 0.203 \\
17 & 8 & 776 & 0.214 & 0.203 \\
9 & 15 & 1,370 & 0.268 & 0.245 \\
15 & 2 & 1,370 & 0.268 & 0.245 \\
8 & 16 & 900 & 0.268 & 0.245 \\
16 & 2 & 900 & 0.268 & 0.245 \\
\hline
\end{tabular}

Table 2. 33kV load data of the Jericho grid

\begin{tabular}{lll}
\hline Load Number & P (MW) & P.F \\
\hline L1 & 1 & 0.98 \\
L2 & 1 & 0.97 \\
L3 & 8 & 0.95 \\
L4 & 2 & 0.97 \\
L5 & 10 & 0.98 \\
\hline
\end{tabular}

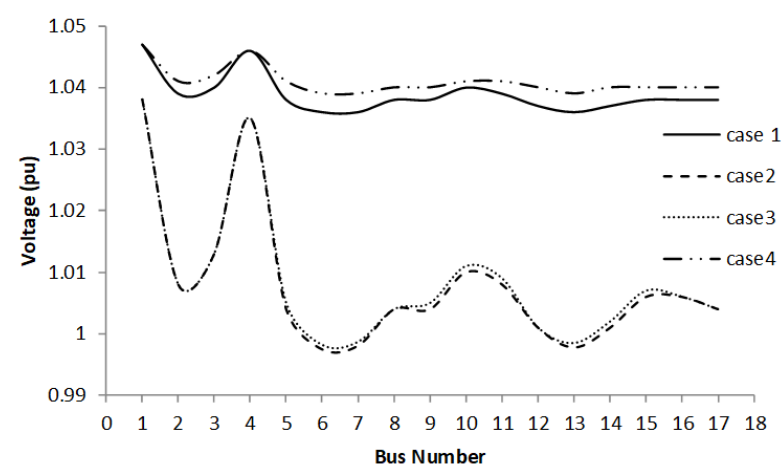

Figure 5. The voltage profile (pu) at each bus at the network

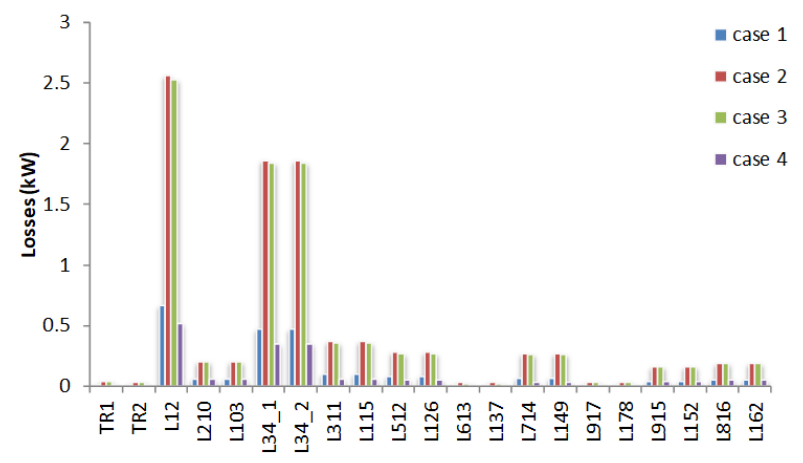

Figure 6. Power losses at the system

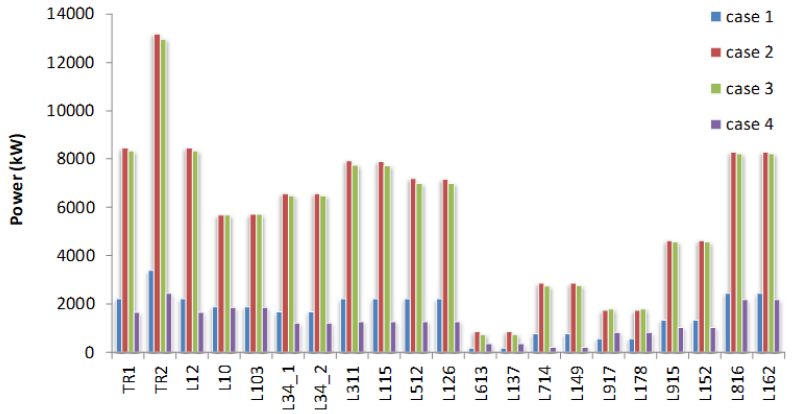

Figure 7. The Power flow at the system

Table 3. Investment cost

\begin{tabular}{llll}
\hline Description & Quantity & Unit price $\$$ & Total price \$ \\
\hline Total cost of PV modules & 5130 & 220 & 1128600 \\
Total cost of inverters & 40 & 3500 & 140000 \\
Design and engineering & 1 & 20000 & 20000 \\
Civil works & 1 & 980000 & 500000 \\
Installation labor cost & 1 & 3000 & 3000 \\
Distribution transformers & 3 & 15000 & 45000 \\
MV switchgear & 1 & 60000 & 60000 \\
MV cables cost & 1 & 5000 & 5000 \\
Batteries costs & 1430 & 50 & 71500 \\
Total Investment cost & & $1,973,100$ & \\
\hline
\end{tabular}

Table 4. Operational Cost

\begin{tabular}{lll}
\hline$\#$ & Description & Cost $\$$ \\
\hline 1. & Production building costs, and water & 10,000 \\
2. & Salary fund & 30,000 \\
3. & Plant and equipment maintenance & 15,000 \\
4. & Office costs & 5,000 \\
5. & Other costs and land tax & 25,000 \\
6. & Insurance & 15,000 \\
7. & Source material & 5,000 \\
8. & Batteries replacement costs & 14,300 \\
9. & Total Operation Cost & 119,300 \\
\hline
\end{tabular}

The main income of the project is provided by selling the generated electricity to the distribution company. The amount of the generated electricity from the PV plant is expected to be $3,427,350 \mathrm{kWh} / \mathrm{yr}$. The selling cost is expected to be around $\$ 0.18$ per $\mathrm{kWh}$. However, the total income of the project is expected to be around $\$ 616,923$ per year. Fig. 8 explains the cumulative cash flow of the project during the lifetime of the project which is expected to be around 20 years. The payback period is expected to be .5 years and the Net Present Value (NPV) is about $\$ 3,885,125.91$. The Internal Rate of Return (IRR) for the project during a 20-year lifespan is about $26 \%$.

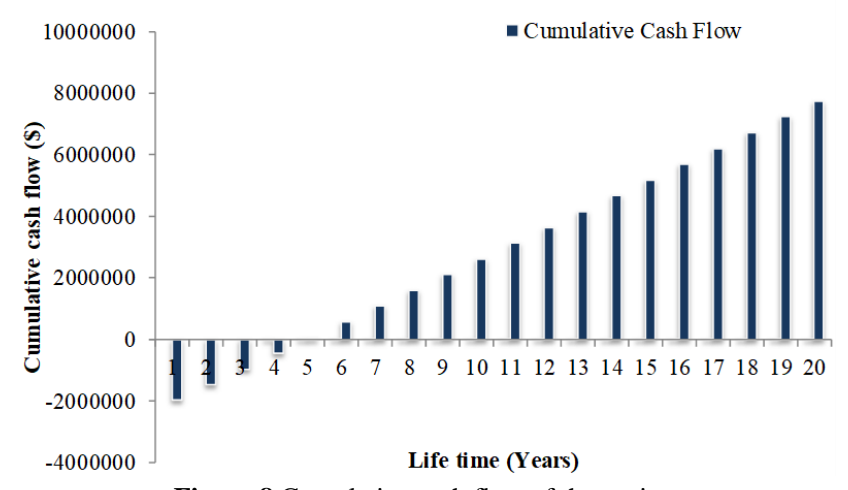

Figure 8 Cumulative cash flow of the project 


\section{Conclusion}

In this paper, two photovoltaic system designs are introduced; of which one is a grid connected with a total capacity 1.5 MVA and is designated to be installed in Jericho City (the Industrial Area). The second system is a standalone one with a $50 \mathrm{~kW}$ capacity and is located in the periphery of Jericho. The factors that affect the design and sizing of the systems have also been presented. Over and under-sizing energy have been avoided to ensure an adequate, reliable and economical system design. Several cases of load and generation have been studied using the OpenDSS program and the results have been compared with respect to voltage profile, power flow and energy losses. The results have shown a good enhancement in the total energy losses and voltage profile in reference to load and generation capacity. The results have shown a good enhancement in the total energy losses and voltage profile in reference to load and generation capacity. However, the voltage profile is enhanced on buses located close to the proposed PV plant while the profile enhancements decrease when moving closer to the source buses. The maximum increase in voltage profile is $0.4 \%$ which is satisfactory in our case. Furthermore, the power losses were clearly decreased with installed of PV systems.

An economic analysis for the on-grid system has been implemented and the results have shown a positive NPV index. It was found that the total income of the project is expected to be around $\$ 616,923$ per year. Further, the payback period is expected to be .5 years and the Net Present Value (NPV) is about $\$ 3,885,125.91$. The Internal Rate of Return (IRR) for the project during a 20-year lifespan is about $26 \%$. The same procedures could be employed and adapted to applications with larger energy consumptions and could also be employed for other geographical locations. However, the appropriate design parameters for these locations should be taken into consideration.

\section{References}

[1] D. G. f. Sonnenenergie, Planning and Installing Photovoltaic Systems: A Guide for Installers, Architects and Engineers. Earthscan, 2008.

[2] M. Al-Maghalseh, "Experimental Study to Investigate the Effect of Dust, Wind Speed and Temperature on the PV Module Performance," Jordan Journal of Mechanical \& Industrial Engineering, vol. 12, no. 2, 2018.

[3] H. Guda and U. Aliyu, "Design of a Stand-Alone Photovoltaic System for a Residence in Bauchi," International Journal of Engineering and Technology, vol. 5, no. 1, pp. 34-44, 2015.

[4] M. M. Al-Maghalseh, "The Impacts of Distribution Generators Size and Location on Power Efficiency and Voltage Profile in Radial LV Networks."
[5] L. Luo et al., "Optimal siting and sizing of distributed generation in distribution systems with PV solar farm utilized as STATCOM (PV-STATCOM)," Applied Energy, vol. 210, pp. 1092-1100, 2018/01/15/ 2018.

[6] S. Freitas, T. Santos, and M. C. Brito, "Impact of large scale PV deployment in the sizing of urban distribution transformers," Renewable Energy, vol. 119, pp. 767776, 2018/04/01/ 2018.

[7] J. Abushnaf and A. Rassau, "Impact of energy management system on the sizing of a grid-connected PV/Battery system," The Electricity Journal, vol. 31, no. 2, pp. 58-66, 2018/03/01/ 2018.

[8] S. Das and A. K. Akella, "Power Flow Control of PVWind-Battery Hybrid Renewable Energy Systems for Stand-Alone Application," International Journal of Renewable Energy Research (IJRER), vol. 8, no. 1, pp. 36-43, 2018.

[9] S. Mandal, B. K. Das, and N. Hoque, "Optimum sizing of a stand-alone hybrid energy system for rural electrification in Bangladesh," Journal of Cleaner Production, vol. 200, pp. 12-27, 2018.

[10] N. Hamrouni, M. Jraidi, A. Dhouib, and A. Cherif, "Design of a command scheme for grid connected PV systems using classical controllers," Electric Power Systems Research, vol. 143, pp. 503-512, 2017/02/01/ 2017.

[11] H. Maammeur, A. Hamidat, L. Loukarfi, M. Missoum, K. Abdeladim, and T. Nacer, "Performance investigation of grid-connected PV systems for family farms: case study of North-West of Algeria," Renewable and Sustainable Energy Reviews, vol. 78, pp. 1208-1220, 2017/10/01/ 2017.

[12] H. A. Kazem, A. H. A. Al-Waeli, M. T. Chaichan, A. S. Al-Mamari, and A. H. Al-Kabi, "Design, measurement and evaluation of photovoltaic pumping system for rural areas in Oman," Environment, Development and Sustainability, journal article vol. 19, no. 3, pp. 10411053, June 012017.

[13] M. Al-Maghalseh, S. Odeh, and A. Saleh, "Optimal sizing and allocation of DGs for real power loss reduction and voltage profile improvement in radial L.V networks," in 2017 14th International Conference on Smart Cities: Improving Quality of Life Using ICT \& IoT (HONET-ICT), 2017, pp. 21-25.

[14] R. Hasan, S. Mekhilef, M. Seyedmahmoudian, and B. Horan, "Grid-connected isolated PV microinverters: A review," Renewable and Sustainable Energy Reviews, vol. 67, pp. 1065-1080, 2017/01/01/ 2017.

[15] A. Kyritsis et al., "Evolution of PV systems in Greece and review of applicable solutions for higher penetration levels," Renewable Energy, vol. 109, pp. 487-499, 2017/08/01/ 2017.

[16] R. H. Ashique, Z. Salam, M. J. Bin Abdul Aziz, and A. R. Bhatti, "Integrated photovoltaic-grid dc fast charging system for electric vehicle: A review of the architecture and control," Renewable and Sustainable Energy Reviews, vol. 69, pp. 1243-1257, 2017/03/01/ 2017.

[17] S. Wagh and P. Walke, "REVIEW ON WIND-SOLAR HYBRID POWER SYSTEM," 2017. 
[18] J. P. Ram, T. S. Babu, and N. Rajasekar, "A comprehensive review on solar PV maximum power point tracking techniques," Renewable and Sustainable Energy Reviews, vol. 67, pp. 826-847, 2017/01/01/2017.

[19] M. M. Al-Maghalseh, A. K. Abutemeha, and M. Iyadiyyeh, "Modeling a hybrid system for electrical generation and wastewater treatment using photovoltaic and fuel cells," (in English), Desalination and Water Treatment, vol. 100, pp. 250-257, 2017.

[20] M. M. A. Al-Maghalseh, "Evaluating the Reliability worth Indices of Electrical Medium Voltage Network: Case Study," Procedia Computer Science, vol. 130, pp. 744-752, 2018/01/01/ 2018.

[21] M. M. Al-Maghalseh and E. M. Maharmeh, "Economic and Technical Analysis of Distributed Generation Connection: A Wind Farm Case Study," Procedia Computer Science, vol. 83, pp. 790-798, 2016.

[22] M. Al-Maghalseh and W. Saleh, "Design and cost analysis of biogas based power plant: Jenin perspective," in 2017 14th International Conference on Smart Cities: Improving Quality of Life Using ICT \& IoT (HONETICT), 2017, pp. 31-35.

[23] M. Al-Maghalseh, "Techno-economic assessment of biogas energy from animal wastes in central areas of Palestine: Bethlehem perspective," International Journal of Energy Applications and Technologies, vol. 5, no. 3, pp. 119-126. 